\title{
O cidadão e a sua formação no Brasil atual: os papéis do Estado e do professor
}

The citizen and his education in hodiernal Brazil: the roles of the state and the teacher

Marco Antônio da Costa*

Universidade Federal de Lavras

Resumo Este artigo objetiva discorrer sobre a formação do cidadão no Brasil atual, destacando os papéis que o Estado e o conjunto de professores desempenham nesse processo formativo. Metodologicamente, este trabalho baseia-se na revisão da bibliografia concernente ao assunto nele abordado. Assim, partindo da reflexão contemporânea sobre os conceitos de cidadão e cidadania, o texto traz uma abordagem crítica tanto das políticas públicas educacionais formuladas e implementadas no âmbito da União, dos estados e dos municípios a partir da década de 1990 quanto do trabalho docente ora desenvolvido nas escolas públicas brasileiras. Com isso, pretende-se discutir como o Estado e o professorado, atores essenciais no contexto educacional, podem contribuir para o processo da formação cidadã.

PAlaVRAS-ChAVE: Cidadão; Educação; Políticas públicas.

Abstract This article aims to discuss the citizen education in hodiernal Brazil, by highlighting the role that both the state and the teachers play in this training process. Methodologically, this work is based on the review of the literature concerning the subject approached in it. Thus, from the contemporary reflection about the concepts of citizen and citizenship, the text brings a critical approach not only of educational public policies formulated and implemented within the Union, states and municipalities from the 1990s but also of the teaching work developed in Brazilian public schools nowadays. With that, it is intended to discuss how the state and the teachers, key actors in the educational setting, can contribute to the process of citizenship education.

KEYWORDS: Citizen; Education; Public policies. 


\title{
Introdução
}

O Brasil das primeiras décadas do século XXI ainda apresenta as mesmas mazelas relacionadas aos baixos índices de educação e de cidadanização de grande parte de sua população. Portanto, a necessidade da reflexão acerca do impacto do sistema educacional na formação de um cidadão crítico e capaz de exercer plenamente a sua cidadania continua tão atual quanto o era no século passado. Evidentemente, o cenário brasileiro reforça cada vez mais a ideia de que o entendimento de alguns importantes aspectos referentes à relação entre formação cidadã, políticas públicas educacionais e prática docente deve ser adquirido tanto pelos que militam direta e cotidianamente no campo educacional quanto pelo conjunto da sociedade. Sem a pretensão de oferecer soluções mágicas para a formação cidadã no Brasil atual, este artigo visa a refletir sobre como o Estado e o professorado brasileiro têm agido em relação a tal formação. Inicialmente, apresentam-se alguns conceitos de cidadão formulados por importantes autores; em seguida, aborda-se a atuação estatal na formação do cidadão; por último, verifica-se como o professorado pode influenciar o desenvolvimento da consciência cidadã dos alunos.

\section{Conceitos contemporâneos de cidadão/cidadania}

Para entendermos o significado dos termos cidadão e cidadania, poderíamos rever o que os antigos gregos e romanos diziam sobre eles. Entretanto, esse não parece ser o procedimento mais apropriado, pois, como observa o professor de História Norberto Guarinello, da USP,

\begin{abstract}
a cidadania nos Estados-nacionais contemporâneos é um fenômeno único na História. Não podemos falar de continuidade do mundo antigo, de repetição de uma experiência passada e nem mesmo de um desenvolvimento progressivo que unisse o mundo contemporâneo ao antigo. São mundos diferentes, com sociedades distintas, nas quais pertencimento, participação e direitos têm sentidos diversos. (GUARINELLO, 2013, p. 29).
\end{abstract}

Assim, é conveniente que nos concentremos em algumas conceituações formuladas por autores contemporâneos que procuraram esclarecer o significado de cidadão e de cidadania à luz do contexto sócio-político-econômico do início do século XXI.

Para Severino (2000), ser cidadão é agir de forma intencional e crítica nas esferas do trabalho (prática produtiva), da sociedade (prática política) e da cultura (prática simbolizadora), pois é essa ação que humaniza os indivíduos, fazendo com que eles deixem de ser apenas seres biológicos e passem a assumir a condição de seres "culturais".

Já para Nascimento (2011), o cidadão, isto é, o ser humano devidamente socializado, é formado pela tríade ensinar-aprender-trabalho, cuja atuação faz com que o indivíduo não fique limitado à esfera biológica, mas se envolva nas atividades culturais, políticas e sociais. Segundo essa autora, “[...] não basta vir ao mundo para dizer-se humano. O tripé ensinar-aprender-trabalho é que produz as condições existenciais para tornar-se humano." (NASCIMENTO, 2011, p. 317). 
Por sua vez, o historiador Jaime Pinsky oferece um interessante comentário sobre o que vem a ser cidadão e cidadania:

Ser cidadão é ter direito à vida, à liberdade, à propriedade, à igualdade perante a lei: é, resumo, ter direitos civis. É também participar no destino da sociedade, votar, ser votado, ter direitos políticos. Os direitos civis e políticos não asseguram sem os direitos sociais, aqueles que garantem a participação do indivíduo na riqueza coletiva: o direito à educação, ao trabalho, ao salário justo, à saúde, a uma velhice tranquila. Exercer a cidadania plena é ter direitos civis, políticos e sociais. (PINSKY, 2013, p. 10).

Finalmente, Jessé Souza, no livro $A$ construção social da subcidadania, também oferece uma importante reflexão sobre os conceitos de cidadão e de cidadania. Ele parte da ideia de que o problema crucial de uma sociedade periférica como a brasileira é a naturalização da desigualdade, ou seja, o fato de que as pessoas veem as diferenças sócio-político-econômicas como naturais e inevitáveis. Para o autor, esse problema decorre da "existência de redes invisíveis e objetivas que desqualificam os indivíduos e grupos sociais precarizados como subprodutores e subcidadãos, e isso sob a forma de uma evidência social insofismável, tanto para os privilegiados como para as próprias vítimas da precariedade."(SOUZA, 2012, p. 177). Assim, lutar para a efetiva transformação social implica em tomar consciência dessa 'ideologia espontânea do capitalismo'. Evidentemente, para que essa tomada de consciência ocorra de forma efetiva e libertadora, faz-se indispensável a atuação de um sistema educacional verdadeiramente comprometido com os interesses das camadas sociais desprivilegiadas.

Para Souza, a subcidadania, isto é, a condição de indivíduos que se colocam à margem do sistema sociopolítico-econômico, é provocada pela combinação do abandono desses indivíduos por parte de importantes instituições, em especial o Estado, e da inadaptação que eles apresentam em relação ao referido sistema pelo fato de não terem desenvolvido as precondições sociais e psicossociais para nele viverem exitosamente, pois, segundo Souza (2012, p. 160), as sociedades modernas procuram "homogeneizar e generalizar, em medida significativa, um tipo humano para todas as classes, como uma precondição para uma efetiva e atuante ideia de cidadania”.

A fim de desenvolver seu argumento, Souza lança mão das concepções de habitus primário, habitus precário e habitus secundário, dos quais aqui nos interessam apenas os dois primeiros, concepções essas construídas a partir do conceito de habitus formulado pelo sociólogo francês Pierre Bourdieu. O habitus bourdiano define-se como "um sistema de estruturas cognitivas e motivadoras, ou seja, um sistema de disposições duráveis inculcadas desde a mais tenra infância que pré-molda possibilidades e impossibilidades, oportunidades e proibições, liberdades e limites de acordo com as condições objetivas." (SOUZA, 2012, p. 45). O habitus primário, cujo desenvolvimento capacita indivíduos e grupos a viverem em uma sociedade moderna, corresponde ao habitus de Bourdieu. Por sua vez, o habitus precário, característico de indivíduos e grupos que não desenvolveram as precondições exigidas para o sucesso no sistema capitalista e que, por isso, tornam-se inadaptados em relação a ele, conduz as pessoas à marginalização, impossibilitando-as de viverem como cidadãos plenos. 
A partir das ideias dos autores citados acima, podem-se observar dois pontos importantes: a) vivemos em uma época repleta de novos desafios e de muitas contradições; b) a educação é o grande elemento capaz de efetivar o processo de cidadanização, ou seja, de transformação de um indivíduo em um verdadeiro cidadão, consciente de seus direitos e deveres, participativo nos processos decisórios de sua comunidade e apto a viver na pós-modernidade de forma crítica e construtiva. Esse último ponto é também enfatizado da seguinte forma por Martins:

A educação não pode e não deve ser o único veículo através do qual os valores da cidadania devem chegar até à população periférica, mas certamente é o mais importante, até porque a instituição escolar é um equipamento social presente em toda periferia e assim sendo deve irradiar estes conceitos e práticas. (MARTINS, 2007, p. 18).

\section{O Estado e a formação do cidadão brasileiro}

O Estado tem um papel de extrema importância na formação do cidadão. A ele cabe assegurar os direitos individuais e coletivos, bem como elaborar e implementar políticas públicas necessárias ao atendimento das necessidades básicas da população, garantindo a ela o acesso aos benefícios decorrentes do desenvolvimento econômico e tecnocientífico da nação. Como o foco deste trabalho concentra-se na educação, faremos a seguir, uma breve discussão sobre as políticas públicas educacionais que têm sido formuladas e, na maioria dos casos, insatisfatoriamente implementadas a partir da década de 1990 no Brasil. Essa discussão é necessária uma vez que a maioria dos estudantes brasileiros depende das escolas públicas para a realização de seus estudos.

Para se entender o que ocorreu no campo educacional brasileiro nos anos de 1990, convém que remontemos à década de 1980, quando o Brasil passava por um período de abertura política. A realização de movimentos como o Diretas Já, que conseguiu levar milhões de pessoas às ruas em todo o País, encorajava o povo a lutar por direitos sociais que demandavam reformas estruturais nos mais diversos setores do Estado e da sociedade. Depois de anos sob os desmandos da ditadura militar, finalmente o povo brasileiro vislumbrava o iminente estabelecimento de uma nova realidade político-social que se pautaria em princípios realmente democráticos. Entretanto, a conjuntura histórica mundial da época conspirou contra o pleno êxito da incipiente luta por reformas sociais no Brasil, como se pode depreender do comentário de Peroni:

O Brasil viveu um processo de abertura pactuado com as forças da ditadura. E, quando estava avançando alguns passos na participação popular e na luta por direitos sociais, sofreu o impacto das estratégias do capital para superação de sua crise: neoliberalismo, globalização e reestruturação produtiva, que já estavam em curso no resto do mundo e vinham em sentido contrário a esse movimento. (PERONI, 2007, p. 16).

Como resultado da crise capitalista deflagrada nos anos 1980, na década de 1990 a política pública educacional brasileira passou a caracterizar-se por dois elementos principais: a subordinação às exigências de determinados organismos internacionais e a ênfase na preparação para o mercado de trabalho. 
A influência externa de organismos internacionais, dentre os quais se destacam a Organização das Nações Unidas para a Educação, a Ciência e a Cultura (UNESCO) e o Banco Mundial, começou a se realizar por meio do exercício de uma forte pressão para a implementação de reformas educacionais no Brasil.

Quanto à ênfase na preparação para o mercado de trabalho em detrimento de uma formação integral do ser humano, percebe-se que ela foi motivada pela necessidade de reestruturação produtiva do sistema capitalista, pois o mercado começou a necessitar de um trabalhador cuja educação coadunasse com as exigências da nova realidade econômica, social e tecnológica. Relativamente ao contexto da reestruturação produtiva, Maron e Maron Neto (2011, p. 9) ressaltam que

\begin{abstract}
a escola passou a ser considerada, do ponto de vista burguês e do senso comum, uma mera fábrica de mão-de-obra para atender às necessidades e interesses do mercado de trabalho. E as políticas de formação implantadas nas escolas e nos espaços produtivos foram promotoras de ajustamento técnico para a execução do trabalho, buscando atender às novas exigências competitivas do sistema de produção.
\end{abstract}

Tanto a pressão de organismos externos quanto a ênfase na preparação para o mercado de trabalho influenciaram grandemente a redação final dos documentos oficiais relacionados à educação brasileira, os quais, se por um lado resultaram em muitas e inegáveis conquistas para grande parte da população, por outro lado preocuparam-se em garantir a manutenção dos interesses do capital. Evidentemente, o resultado não seria favorável aos grupos que reivindicavam a instauração de uma escola genuinamente democrática no Brasil. Comentando especificamente as modificações trazidas pela nova Lei de Diretrizes e Bases da Educação Nacional (LDBEN) promulgada em 1996, Oliveira faz o seguinte comentário:

Essas modificações ocorrem em um contexto no qual, tendencialmente, regulariza-se o fluxo no Ensino Fundamental, impulsionado de forma ambígua tanto por uma perspectiva democratizadora quanto por uma de economia de recursos. Isto fará que, em breve, todos tenham oito anos de escolarização, mas não o acesso aos mesmos níveis de conhecimento. Muitos, nem a patamares mínimos. Elimina-se, assim, a exclusão do Ensino Fundamental, não a exclusão do acesso ao conhecimento. Modifica-se apenas a forma de explicitação dessa exclusão. (OLIVEIRA, 2000, p. 78).

Ainda na década de 1990, inicia-se, em 1995, a prática da avaliação institucional com o Sistema de Avaliação da Educação Básica (Saeb). A intenção declarada pelo governo era proceder à avaliação da educação brasileira a fim de empreender posteriores ações capazes de elevar o nível qualitativo dos sistemas de ensino. Segundo a já citada LDBEN, em seu artigo nono, inciso VI, uma das incumbências do Governo Federal é "assegurar processo nacional de avaliação do rendimento escolar no ensino fundamental, médio e superior, em colaboração com os sistemas de ensino, objetivando a definição de prioridades e a melhoria da qualidade do ensino."

Entretanto, embora tenha contribuído para dar mais transparência aos resultados do trabalho no campo educativo, a adoção de sistemas de avaliação institu- 
cional evidenciou a mudança da postura do Estado quanto à educação, visto que ele passou de executor da política educacional a um mero financiador e avaliador dessa política. Era mais uma vitória do capital sobre o social, como observa Peroni:

Mais especificamente na política educacional, ao mesmo tempo em que avançamos na luta por uma educação para todos, o Estado passa de executor a apenas o avaliador e indutor da qualidade através da avaliação. A gestão democrática passa a dar lugar para a gestão empresarial, já que o mercado é parâmetro de qualidade. (PERONI, 2008, p. 13).

Atualmente o Saeb compõe-se de três avaliações externas em larga escala: a Avaliação Nacional da Educação Básica (Aneb); a Avaliação Nacional do Rendimento Escolar (Anresc), também conhecida como "Prova Brasil"; e a Avaliação Nacional da Alfabetização (ANA). Enquanto as duas primeiras são realizadas a cada dois anos, a terceira realiza-se anualmente.

Além das três avaliações externas que compõem o Saeb, temos o Exame Nacional de Desempenho de Estudantes (Enade), criado em 2007 para avaliar o Ensino Superior, e outros inúmeros mecanismos de avaliação utilizados por prefeituras e estados para avaliar o ensino oferecido em suas redes de ensino.

Apesar da farta variedade que os governantes têm para avaliar a educação, constata-se que as políticas públicas educacionais elaboradas com base nas avaliações externas não têm sido bem sucedidas, pois, conforme matéria do Estadão, de 02/07/2014, um recente estudo do Banco Interamericano de Desenvolvimento (BID) mostra que apenas 58\% dos estudantes brasileiros concluem o Ensino Médio (85\% entre os mais ricos e - assuste-se - $28 \%$ entre os de menos recursos). Além disso, segundo o mesmo estudo, em um ranking de 65 países o Brasil ocupa a 59a posição em Ciências, a $58^{\mathrm{a}} \mathrm{em}$ Matemática e a $55^{\mathrm{a}} \mathrm{em}$ Leitura ${ }^{1 .}$ Esse fragoroso insucesso brasileiro no campo educativo revela que a ação do Estado avaliador mostra-se altamente ineficaz para promover a elevação da qualidade do ensino, isso porque, segundo matéria da revista Nova Escola sobre o estudo A Avaliação Externa como Instrumento da Gestão Educacional nos Estados, da Fundação Victor Civita (FVC), a cultura da avaliação provoca o surgimento dos seguintes mitos:

- O Saeb avalia a aprendizagem dos alunos

- A avaliação é a radiografia da Educação do país

- Os docentes mudam a prática com o anúncio de notas

- As avaliações sempre são usadas para o replanejamento

- É possível avaliar a aprendizagem sem um currículo

- A escola que vai bem em uma avaliação é boa

- A competição leva à melhoria do ensino

- Os alunos vão mal por culpa do professor ${ }^{2}$ 
Embasada nas opiniões de vários especialistas da área educacional, a referida matéria indica que os oito mitos listados acima não correspondem absolutamente ao que se verifica no cotidiano dos sistemas de ensino, mas, de modo geral, são ideias ingenuamente sustentadas pela sociedade, pelos governantes e pelos tecnocratas que elaboram as políticas educacionais no Brasil. Portanto é mais do que necessário que o Estado não se limite à cultura da avaliação externa para orientar a formulação de suas políticas educacionais.

Um exemplo de política pública educacional implementada na década de 1990 foi o Programa Escola Plural, implantado de forma pioneira no Brasil na Rede Municipal de Ensino de Belo Horizonte (RME-BH) em 1995 (1º e $2^{\circ}$ ciclos) e em 1996 (3º ciclo), objetivando reverter o baixo nível de aprendizagem que gerava um alto índice de repetência e de evasão escolar dos alunos da referida rede.

Em sua dissertação de Mestrado, Ferreira (2009) entrevistou alguns professores da RME - BH que acompanharam na prática o processo de renovação pedagógica que dera origem à implantação da Escola Plural, os quais apresentaram várias críticas a esse programa educacional, tais como: 1 ) suas propostas curriculares foram feitas sem a devida participação do professorado; 2) seu sistema original de avaliação (sistema no qual o aluno não recebia uma nota numérica, mas tinha o seu desempenho escolar encaixado em um conceito percentual que variava de A a E, cada letra perfazendo $20 \%$ do total de pontos distribuídos) constituía uma estratégia para mascarar o baixo desempenho do aluno e facilitar sua aprovação; 3) sua implantação ocorreu de forma descontextualizada; 4) sua capacidade de elevar o nível de aprendizagem é altamente enganoso, visto que se verifica a existência de uma distância considerável entre o discurso autopropagandista do governo municipal e a realidade vivenciada nas escolas.

Essas críticas feitas pelos professores da RME - BH à Escola Plural assemelham-se a outras relacionadas à quase totalidade das políticas públicas educacionais formuladas e implementadas Brasil afora a partir da década de 1990. Mudam-se os municípios e os estados, mas as queixas e os problemas relativos a essas políticas são sempre os mesmos. Os docentes continuam tendo uma participação extremamente limitada tanto nos processos de formulação e implementação das políticas educacionais quanto na elaboração das propostas curriculares; os métodos avaliativos comumente são aplicados para maquiar o real desempenho dos alunos e apresentar uma boa imagem dos governos diante dos organismos internacionais; geralmente essas políticas se espelham em ideias educacionais concebidas e praticadas em outros países, desconsiderando a especificidade de nossas realidades regionais; e, por fim, a aprendizagem efetiva dos alunos normalmente fica muito aquém do esperado. De fato, verifica-se a incômoda continuidade de uma série de problemas crônicos na educação brasileira, o que leva não apenas à sensação, mas ao inevitável e comprovado reconhecimento de que "o estado continua ausente na questão da educação ou faz muito pouco, deixando ainda a maior responsabilidade para o mercado. A luta pelo direito à educação de qualidade para todos e todas não alcançou ainda seus grandes objetivos". (GADOTTI, 2012, p. 15). 
Para Lobo Neto (2009), a ineficiência das políticas públicas educacionais brasileiras consiste no fato de elas se caracterizarem como políticas de governo e não de Estado. Em outras palavras, tais políticas encontram-se intimamente conectadas ao programa de governo de um partido político ou de uma coligação hegemônica, sendo implantadas prioritariamente com vistas à propaganda política. Assim, quando outro grupo político suplanta o anterior em determinada eleição, uma nova política é implementada, interrompendo a continuação de medidas que estariam obtendo um bom resultado. $\mathrm{O}$ autor define o que, em sua opinião, constitui uma política educacional "plenamente pública":

Um primeiro aspecto para caracterizar o plenamente público é muito óbvio e esquecido: o interesse da maioria trabalhadora. O fato de não poder cair na ingenuidade de esquecer que se está em uma sociedade de classes, em que a minoria detém o poder hegemônico, não a exime de buscar a nitidez dos interesses da maioria nesta especificidade educacional que the diz diretamente respeito. (LOBO NETO, 2009, p. 99).

De fato, enquanto a sociedade brasileira deseja receber uma educação de boa qualidade, o governo persiste na adoção de políticas públicas educacionais comprovadamente ineficazes. $\mathrm{O}$ resultado não poderia deixar de ser decepcionante, como mostra Martins (2007, p. 16):

A sociedade como um todo deposita na educação a esperança de mudanças e parece haver uma ausência de ações efetivas de governo que não investe adequadamente e ou não consegue entender corretamente a periferia, deixando a população exposta à criminalidade e levando-a a desacreditar nas instituiçôes políticas e sociais e a crer na impunidade como regra.

Certamente, uma educação de má qualidade não qualifica devidamente para o mercado de trabalho, não promove a efetiva formação cidadã nem a tecnológica e muito menos desenvolve a capacidade investigativa das pessoas. Consequentemente, a maioria dos brasileiros, que por fragilidade econômica se vê forçada a receber tal tipo de educação, permanece em uma condição de subcidadania, não tendo acesso a um padrão educacional que the permita agir de forma realmente transformadora na sociedade. Assim, essa parte da população é submetida à perversa exploração do capital e se mantém à margem dos processos decisórios que delineiam o destino da sociedade brasileira.

\section{O professor e a formação do cidadão brasileiro}

Nos novos tempos, necessita-se de uma escola que paute sua ação em princípios democráticos, como observa Gadotti (2000, p. 8): "Espera-se que a educação do futuro seja mais democrática, menos excludente. Essa é ao mesmo tempo nossa causa e nosso desafio". Entretanto, ainda existe um caminho considerável a ser percorrido até a instauração dessa nova realidade educacional, pois, conforme Klein (2006, p. 66), "a escola ignora atitudes discriminatórias: o discurso defende a liberdade de expressão, a igualdade, a tolerância, mas transmite de forma implícita atitudes sexistas, racistas e competitivas". Decorre daí a necessidade de que o professor, figura indispensável 
ao desenvolvimento social, assuma uma prática pedagógica realmente orientada por valores e princípios democráticos a fim de fomentar o estabelecimento de novos comportamentos na comunidade escolar e formar verdadeiros cidadãos.

Repensar a relação professor-aluno é fundamental nessa época em que tal relação encontra-se em uma crise patente. Os noticiários diários têm revelado o crescente surgimento de conflitos entre esses atores sociais, conflitos que não raramente chegam aos tribunais, levando juízes a tomarem decisões que servem muito menos para dirimir as contendas do que para desnudar as mazelas de um relacionamento que, outrora caracterizado por respeito e cooperação, parece assumir uma configuração crescentemente pautada na incivilidade. Apontando aquela que lhe parece ser a principal causa dessa crise relacional, Gadotti $(2012$, p. 28) observa que "a relação professor-aluno tornou-se tensa, agressiva, porque reproduz relações competitivas de mercado. Ela adquiriu a forma do mercado, reproduzindo as relações de produção dominantes na sociedade".

Todavia, como o objetivo maior da educação é desenvolver cidadãos capazes de atuar significativamente na sociedade e que aprendam a refletir criticamente sobre as relações sociais, políticas, econômicas e tecnológicas que configuram o mundo atual e interferem diretamente no destino das pessoas, o professor precisa demonstrar dia a dia aos alunos um alto padrão de democracia mediante práticas que evidenciem respeito aos mais diversos modos de pensar, falar e agir.

A necessidade de formar alunos-cidadãos autênticos deve levar o professor a trabalhar condizentemente com a nova conjuntura histórico-político-social a qual demanda uma educação compreensiva e dialógica.

Uma educação compreensiva procura ensinar as pessoas a se compreenderem, a aceitarem sua condição simultânea de igualdade e diversidade. Saber lidar com o fato de que somos iguais e também diferentes é algo que precisa ser desenvolvido na escola. Segundo Morin (2000), a compreensão é um dos sete saberes necessários à educação do futuro, devendo, portanto, ser ensinada e praticada nas escolas: "O problema da compreensão tornou-se crucial para os humanos. E, por este motivo, deve ser uma das finalidades da educação do futuro". (MORIN, 2000, p. 93). Considerando a incompreensão um elemento que cresce "como um câncer na vida cotidiana" e causa o estremecimento das relações interpessoais e internacionais, esse autor ressalta que o ensino de sua contraparte, a compreensão, é uma forma de implantar um novo modelo de relacionamento humano. É necessário ensinar as pessoas a serem mais compreensivas e tolerantes, não reduzindo o outro a apenas um aspecto de sua vida, mas procurando observá-lo dentro do contexto mais amplo de sua existência, reconhecendo-o como um ser humano dotado de enorme complexidade. Morin vê a compreensão como uma poderosa arma para o enfrentamento do egocentrismo, do etnocentrismo e do sociocentrismo que promovem o desentendimento entre indivíduos, grupos e nações. Assim, percebe-se que a adoção de uma educação compreensiva é uma das maiores contribuições que o professor pode dar para a efetiva democratização da sociedade. 
Além de compreensiva, a educação adequada para os novos tempos deve também ser dialógica, pois o diálogo entre os indivíduos é condição sine qua non para o estabelecimento e a preservação da convivência harmoniosa e construtiva numa sociedade democrática. Especificamente, no ambiente de sala de aula o incentivo ao desenvolvimento de uma rica convivência dialógica possui um alto valor pedagógico, o que é atestado pelos Parâmetros Curriculares Nacionais:

Uma rica interação dialogal na sala de aula, dos alunos entre si e entre o professor e os alunos, é uma excelente estratégia de construção do conhecimento, pois permite a troca de informações, o confronto de opiniões, a negociação dos sentidos, a avaliação dos processos pedagógicos em que estão envolvidos [...] O exercício do diálogo na explicitação, contraposição e argumentação de ideias é fundamental na aprendizagem da cooperação e no desenvolvimento de atitudes de confiança, de capacidade para interagir e de respeito ao outro. (BRASIL, 1998, p. 24, 41).

Portanto, o professor precisa promover um diálogo inteligente e abundante entre os alunos, visando a garantir o envolvimento deles na participação de atividades dentro e fora da sala de aula e a evitar o desenvolvimento de comportamentos discriminatórios entre eles. Porém, uma educação dialógica pretende modificar profundamente não só a relação entre o professor e o aluno, mas entre todos os envolvidos no contexto escolar, pois a construção dessa educação tem como base

\begin{abstract}
a centralidade da relação pedagógica entre educador e educando; a condução das atividades de gestão em torno da relação pedagógica; a socialização da vida escolar com a ampliação do poder de intervenção dos educandos, pais e demais membros da sociedade civil na decisão da escola; e a avaliação diagnóstica em lugar de uma avaliação meramente punitiva. (RODRIGUES, 2009, p. 16).
\end{abstract}

A luta pelo estabelecimento de uma educação verdadeiramente democrática e democratizante por meio da qual o ensinar e o aprender tornem-se experiências realmente gratificantes, colaborativas e respeitosas, acarreta para o professor a necessidade da adoção de uma nova postura enquanto profissional e ser humano. Apesar do desenvolvimento alucinante da informatização típica da sociedade contemporânea, o professor continua tendo um papel relevante para a formação cidadã dos alunos e, por isso, deve repensar constantemente a sua prática de educar e de se educar.

\title{
Considerações finais
}

Pelo que foi exposto nas páginas anteriores, percebe-se que no contexto sociocultural brasileiro, ser cidadão é algo que ainda não se realizou na vida de grande parte da população. Evidentemente, a precária situação da área educativa contribui de forma decisiva para que essa falta de cidadania plena perdure já por centenas de anos. Especialmente nesta era pós-moderna, repleta de novas e crescentes exigências tecnológicas, econômicas, políticas e sociais, a educação brasileira tem se mostrado ineficiente para municiar as pessoas com as armas necessárias para o enfrentamento das rápidas mudanças. 
Possuir e exercer uma efetiva cidadania demanda conhecimento crítico e socialmente construtivo que leve os indivíduos a agirem em prol da construção de uma nova realidade. Sem dúvida, um ambiente escolar de qualidade é um dos melhores lugares onde esse conhecimento pode ser desenvolvido. Assim, cabe a todos os envolvidos no âmbito educativo (gestores, professores, técnicos, alunos e familiares) contribuir para a reversão do atual quadro de precariedade e de ineficiência da educação brasileira, isso porque, como observa Severino (2000, p. 71), a educação pode ser um "elemento gerador de novas formas de concepções de mundo capazes de se contraporem à concepção de mundo dominante em determinado contexto sociocultural."

Em suma, a formação e o exercício de uma autêntica cidadania no Brasil demandam urgentemente a instauração de uma nova realidade educacional. Nesse sentido, faz-se necessária a ocorrência da elaboração e implementação de políticas públicas realmente voltadas para a elevação do nível de qualidade da educação e que efetivamente promovam a melhoria qualitativa da formação inicial e continuada do professorado. Caso contrário, por mais que continuemos sonhando e lutando, o agravamento da desigualdade social, a marginalização de parte da população, a desqualificação para o mercado de trabalho, tudo isso insistirá em permanecer no seio desta ainda esperançosa sociedade.

\section{Referências}

BRASIL. Casa Civil. Lei no 9.394 (1996). Lei de Diretrizes e Bases da Educação Nacional, de 20 de dezembro de 1996. Disponível em: <http://www.planalto.gov.br/ccivil_03/leis/19394. $\mathrm{htm}>$. Acesso em: 25 jan. 2015.

BRASIL. Secretaria de Educação Fundamental. Parâmetros curriculares nacionais: terceiro e quarto ciclos do ensino fundamental: língua portuguesa. Brasília: MEC/SEF, 1998. Disponível em: <http://portal.mec.gov.br/seb/arquivos/pdf/portugues.pdf >. Acesso em: 18 jan. 2015.

FERREIRA, C. S. A Escola Plural anos depois: a voz de gestores e docentes. 2009. Dissertação (Mestrado em Educação) - Faculdade de Educação, Universidade Federal de Minas Gerais, Belo Horizonte, 2009. Disponível em: <http://www.bibliotecadigital.ufmg.br/dspace/bitstream/handle/1843/BUBD-92QLAY/dissertacao_claudia_silva_ferreira.pdf?sequence=1 >. Acesso em: 26 jan. 2015.

GADOTTI, M. Perspectivas atuais da educação. São Paulo em Perspectiva, v. 14, n. 2, p. 3-11, 2000. Disponível em: <http://www.scielo.br/pdf/spp/v14n2/9782.pdf >. Acesso em: 12 jan. 2015.

Educação Popular, Educação Social, Educação Comunitária: conceitos e práticas diversas, cimentadas por uma causa comum. Revista Diálogos: pesquisa em extensão universitária, v. 18, n. 1, p. 10-32, dez. 2012. Disponível em: <http://portalrevistas.ucb.br/index.php/RDL/ article/viewFile/3933/2406>. Acesso em: 13 jan. 2015.

GUARINELLO, N. L. Cidades-estado na antiguidade clássica. In: PINSKY, J.; PINSKY, C. B. (Orgs.). História da cidadania. 6 ed. São Paulo: Contexto, 2013.

KLEIN, A. M. Escola e democracia: um estudo sobre a representação de alunos e alunas do Ensino Médio. 2006. Dissertação (Mestrado em Psicologia e Educação) - Faculdade de Educação, Universidade de São Paulo, São Paulo, 2006. Disponível em: <http://www.teses.usp.br/ teses/disponiveis/48/48134/tde-31032006-151616/pt-br.php>. Acesso em: 27 jun. 2014. 
LOBO NETO, F. J. S. A questão da tecnologia na relação trabalho-educação: das concepções aos argumentos e às formulações legais. Trabalho, Educação e Saúde, v. 7, suplemento, p. 83-103, 2009. Disponível em: <http://www.revista.epsjv.fiocruz.br/upload/revistas/r371.pdf>. Acesso em: 10 fev. 2015.

MARON, N. M.W.; MARON NETO, E. Tecnologia e trabalho nos processos de formação humana. Anais dos Simpósios Nacionais de Tecnologia e Sociedade, 2011. Disponível em: <http://www.esocite.org.br/eventos/tecsoc2011/cd-anais/arquivos/pdfs/artigos/gt015-tecnologiae.pdf>. Acesso em: 28 jan. 2015.

MARTINS, C. A. Violência, educação, subcidadania e democracia na periferia da grande metrópole. 2007. Dissertação (Mestrado em Geografia Humana) - Faculdade de Filosofia, Letras e Ciências Humanas, Universidade de São Paulo, São Paulo, 2007. Disponível em: <http:// www.teses.usp.br/teses/disponiveis/8/8136/tde-03122007-111307/pt-br.php>. Acesso em: 25 jan. 2015.

MORIN, E. Os sete saberes necessários à educação do futuro. 2. ed. Brasília: UNESCO, 2000.

NASCIMENTO, I. P. A Pós-Modernidade: uma escuta sobre a nova cultura da Aprendizagem na Escola. Cadernos de Educação, v. 38, p. 315-333, jan./abr. 2011. Disponível em: <http:// periodicos.ufpel.edu.br/ojs2/index.php/caduc/article/viewFile/1573/1459>. Acesso em: $17 \mathrm{jan}$. 2015.

OLIVEIRA, R. P. Reformas educativas no Brasil na década de 90. In: CATANI, A. M.; OLIVEIRA, R. P. (Orgs.). Reformas educacionais em Portugal e no Brasil. Belo Horizonte: Autêntica, 2000. p. 77-94.

PERONI, V. M. V. Reforma do Estado e a tensão entre o público e o privado. Revista SIMPE-RS, Porto Alegre, p. 11-33, abr./2007. Disponível em: <http://www.ufrgs.br/faced/peroni/ docs/Ministerio_Publico_1.pdf>.Acesso em: 11 jan. 2015.

Políticas Públicas e Gestão da Educação em Tempos de Redefinição do Papel do Estado. In: VII SEMINÁRIO DE PESQUISA EM EDUCAÇÃO DA REGIÃO SUL, Itajaí, 2008. Disponível em: <http://www.pead.faced.ufrgs.br/sites/publico/eixo5/organizacao_gestao/modulo1/pol\%EDticas_publicas_e\%20gestao_da_educacao_veraperoni.pdf $>$. Acesso em: 10 jan. 2015.

PINSKY, J. Introdução. In:____ _ PINSKY, J.; PINSKY, C. B. (Orgs.). História da cidadania. 6 ed. São Paulo: Contexto, 2013.

RODRIGUES, R. L. Democratização e cultura no debate educacional brasileiro: tensões e articulações entre igualdade e pluralidade. Vertentes, São João Del-Rei, v. I, n. 13. p. 09-20, 2009. Disponível em: <http://www.ufsj.edu.br/portal2-repositorio/File/Rubens\%20Rodrigues. pdf $>$. Acesso em: 30 jan. 2015.

SEVERINO, A.J. Educação, trabalho e cidadania: a educação brasileira e o desafio da formação humana no atual cenário histórico. São Paulo em Perspectiva, v. 14, n. 2, p. 65-71, 2000. Disponível em: 〈http://www.scielo.br/pdf/spp/v14n2/9790.pdf>. Acesso em: 17 jan. 2015.

SOUZA, J. A construção social da subcidadania: para uma sociologia política da modernidade periférica. Belo Horizonte: UFMG, 2012.

\section{Notas}

\footnotetext{
${ }^{1}$ Disponível em: <http://educacao.estadao.com.br/noticias/geral,falta-de-perspectiva-faz-estudante-abandonar-ensino-medio,1521976>. Acesso em: 27 jul. 2014.

${ }^{2}$ Disponível em: <http://revistaescola.abril.com.br/politicas-publicas/8-mitos-testes-aprendizagem-larga -escala-643599.shtml?page=6>. Acesso em: 27 jul. 2014.
} 
* Professor do Centro Federal de Educação Tecnológica de Minas Gerais, Belo Horizonte, Minas Gerais, Brasil.

\section{Correspondência}

Marco Antônio da Costa - Rua Altamira, 148, bairro Pirajá, CEP: 31910630 - Belo Horizonte, Minas Gerais, Brasil.

E-mail: mtonycosta@gmail.com

Recebido em 04 de março de 2015

Aprovado em 11 de março de 2016 